\title{
К ВОПРОСУ ОБ ОСНОВАНИЯХ УМЕНЬШЕНИЯ И ОТКАЗА В ПРИСУЖДЕНИИ ОБЯЗАТЕЛЬНОЙ ДОЛИ В НАСЛЕДСТВЕ
}

\begin{abstract}
REDUCING AND REFUSING
TO AWARD A MANDATORY SHARE
IN THE INHERITANCE
A. Gudkov

A. Krasilschikov

V. Mishchenko

Summary. The issues discussed in this article concerning the problematic aspects of the mandatory share in the inheritance are of particular relevance in modern conditions. In many cases, the inheritance of this share can improve or maintain the financial situation of the heirs, especially the disabled. In this regard, the article examines the law enforcement practice, the positions of scientists set forth in the legal literature.

Based on the analysis of the mandatory share in the inheritance, the grounds provided for by the civil law for its reduction and refusal to award, conclusions are drawn with the aim of improving the Civil Code of the Russian Federation and aimed at ensuring uniformity of judicial practice. In particular, the authors propose additions to the current edition of Art. 1149 of the Civil Code of the Russian Federation, stipulating in it a provision that the court has the right to consider the property status of heirs with the right to an obligatory share. At the same time, it should be clarified that they have their own property, their participation in the formation of common property with the testator, their joint use, the duration of the marriage, as well as other circumstances. And only guided by the data received, make a decision to reduce the size of the mandatory share or refuse to award it.
\end{abstract}

Keywords: inheritance, share, refusal, award, property, contract, spouse, parents, inheritance, protection, inheritance Fund.
Гудков Анатолий Иванович

К.ю.н., дочент, Владимирский юридический институт ФСИН России gudkovaniv@yandex.ru

Красильщиков Анатолий Владимирович К.ю.н., дочент, Владимирский юридический институm ФСИН России krasilschikov@inbox.ru

Мищенко Вячеслав Иванович

К.ф.н., дочент, Владимирский юридический институт ФСИН России vyacheslav-mischenko@mail.ru

Аннотация. Рассмотренные в настоящей статье вопросы, касающиеся проблемных аспектов обязательной доли в наследстве, в современных условиях имеют особую актуальность. Во многих случаях наследование этой доли позволяет улучшить или сохранить материальное положение наследников, особенно нетрудоспособных. В этой связи в статье исследована правоприменительная практика, позиции ученых, изложенные в юридической литературе.

На основе проделанного анализа обязательной доли в наследстве, предусмотренных гражданским законодательством оснований ее уменьшения и отказа в присуждении, сделаны выводы, имеющие своей целью совершенствование ГК РФ и направленные на обеспечение единообразия судебной практики. В частности, авторы предлагают внесение дополнений

В действующую редакцию ст. 1149 ГК РФ, предусмотрев в ней положение о том, что суд вправе рассмотреть имущественное положение наследников, обладающих правом на обязательную долю. При этом следует уточнить наличие у них собственного имущества, их участие в образовании общей собственности с наследодателем, совместное пользование ею, срок брака, а также иные обстоятельства. И только руководствуясь полученными данными, принимать решение об уменьшении размера обязательной доли или отказе в ее присуждении.

Ключевые слова: наследство, доля, отказ, присуждение, имущество, договор, супруг, родители, наследование, защита, наследственный фонд. 
C овременный мир стремительно меняется. Беспрецедентная ситуация, возникшая во всем мире и в нашей стране из - за пандемии коронавируса, внесла коррективы в деловую активность как крупных корпораций, так и малого и среднего бизнеса, всего предпринимательского сообщества, туристического бизнеса, контактов и перемещений людей между странами и континентами. На смену глобализации приходит, мы убеждены, временная, изоляционная политика, когда первостепенной задачей является, с одной стороны, сохранение главной ценности - человеческой жизни, а с другой,- минимизация негативных последствий пандемии и сохранение достигнутого уровня развития материальной культуры, материального благосостояния и благополучия, на основе которого созданы и продолжают создаваться материальные блага, являющиеся необходимым условием бытия человека.

Но, как известно, человеком движет интерес. Поэтому и в таких непростых условиях не прекращаются интеллектуальная деятельность, научные поиски путей совершенствования гражданского оборота, сохранения и приумножения материальных и духовных ценностей, созданных в процессе созидательной деятельности человека. Это, на наш взгляд, в полной мере относится к научной деятельности, поискам совершенствования сложившихся правовых механизмов регулирования наследственных правоотношений, которые, по нашему мнению, требуют дальнейшего совершенствования.

Положениями действующего в настоящее время гражданского законодательства особым статусом среди наследников по закону наделены несовершеннолетние и нетрудоспособные дети наследодателя, нетрудоспособные супруги и родители, нетрудоспособные иждивенцы наследодателя.

Вышеуказанные лица, выступая в качестве обязательных наследников, наследуют не менее половины той доли, которая причиталась бы каждому из них при наследовании по закону.

Обязательная доля в наследстве рассматривается как своего рода ограничение распоряжения всем своим имуществом, которым обеспечивается защита прав определенных категорий граждан. В частности, в том случае, если наследодатель не составлял завещания и не заключал наследственного договора, предусмотрено наследование имущества по закону, исходя из очередности наследников.

Вместе с тем, при оформлении завещания или же составлении наследственного договора, получить наследство могут и лица, которые в нем прямо указаны, и лица, у которых имеется законное право на это (что прослежи- вается из норм, закрепленных в ч. 1 ст. 1111, п. 1 ст. 1118, п. 6 ст. 1140.1, Ст. Ст. 1141, 1149 ГК РФ [1]).

В юридической литература до настоящего времени не выработан единообразного подхода к сущности обязательной доли в наследстве. В частности, по мнению отдельных авторов при реализации на практике положений об обязательной доле в наследстве происходит как бы «бронирование» части наследственного имущества для особых категорий наследников, вне зависимости от того, что указано в завещании [3. С. 124].

В свою очередь О.С. Иоффе обосновывается позиция, согласно которой обязательная доля - это «минимум» для наследников [6. С. 317].

В соответствии с п. 1 ст. 1149 ГК РФ правом на обязательную долю обладают несовершеннолетние и нетрудоспособные дети умершего гражданина, его супруг и родители. Данное право также есть у нетрудоспособных граждан-иждивенцев умершего (ст. 1148 ГК РФ).

Кроме того, считаем необходимым обратить внимание на то, что согласно правилам, которые вступили в силу 1 сентября 2018 г., в том случае, если обязательный наследник является выгодоприобретателем наследственного фонда, то он утрачивает право на обязательную долю. Восстановить право на обязательную долю возможно путем отказа наследника в течение срока принятия наследства от всех прав выгодоприобретателя наследственного фонда.

Обращаясь к рассмотрению вопроса уменьшения и отказа в присуждении обязательной доли в наследстве, отметим, что суд, рассматривая дело, может уменьшить размер обязательной доли в наследстве, а также отказать в ее присуждении. Подобное решение может быть принято судом не произвольно, а руководствуясь нормой, закрепленной в ст. 1149 ГК РФ.

В частности, если наследником по завещанию наследственное имущество использовалось для проживания (к примеру, лицо проживало в квартире умершего или же квартира использовалась им как основной источник дохода), а наследник, у которого имеется право на получение обязательной доли, при жизни наследодателя не использовал данное имущество. В подобной ситуации и с учетом имущественного положения наследников судом может быть принято такое решение, что прослеживается из материалов судебной практики [2]. Так, согласно Определению Судебной коллегии по гражданским делам Верховного Суда Российской Федерации от 05.11.2019 N5-КГ19-181, истицей было заявлено требование об уменьшении обязательной доли наследства. 
Исходя из обстоятельств дела: наследник по завещанию указывает, что наследник по закону претендует на обязательную долю в наследстве, в том числе на жилое помещение, являющееся для наследника по завещанию единственным жильем, в то время как у наследника по закону в собственности есть недвижимое имущество.

Вынесенным решением дело направлено на новое рассмотрение, так как судом не установлены все обстоятельства, значимые для дела. Так, остались не вполне ясными и не исследовались следующие вопросы: повлечет или нет реализация наследником по закону своих прав невозможность для наследника по завещанию использовать имущество, в котором он при жизни наследодателя жил. При этом также не было учтено, что наследник по завещанию является инвалидом.

Судом также может быть уменьшен размер обязательной доли наследника, который отказался от прав выгодоприобретателя наследственного фонда, в случае, если стоимость причитающегося ему наследства значительно выше размера средств, которые нужны на содержание наследника с учетом его обязательств перед третьими лицами, потребностей и средней величины расходов, уровня его жизни до смерти наследодателя (что следует из абз. 2 п. 5 ст. 1149 ГК РФ).

Обращаясь к рассмотрению отказа от обязательной доли, считаем необходимым детализировать положение о том, что наследник не обязан получить ее, при желании он вправе отказаться от такой доли. Однако применительно к отказу законодательно предусмотрено только одно ограничение: отказ невозможен в пользу другого наследника. Правовым последствием отказа станет увеличение доли наследника по завещанию или наследственному договору (п. 1 ст. 1118 , ст. 1157, п. 1 ст. 1158 ГК РФ).

В юридической литературе высказываются неоднозначные, порой противоречивые, мнения об уменьшении обязательной доли и отказе в ее присуждении. В частности, исходя из позиции Н.Б.Деминой, и так уже произошло снижение размера обязательной доли до 1/2. Ее точка зрения основывается на том, что указанное ограничение негативно влияет на права нетрудоспособных родственников наследодателя, еще больше ослабляя их.

В этой связи она предлагает использование механизма соглашения о разделе наследства, предусмотрев в нем возможность выделения обязательной доли в денежном эквиваленте [5. С. 26].
Однако, существуют и иные позиции и мнения ученых. Так, по мнению С.П. Гришаева получить обязательную долю желают не всегда малоимущие люди [4]. И мы в этом с ним согласны. То есть, иногда вопрос выделения обязательной доли поднимается пережившим супругом (даже если фактические брачные отношения до открытия наследства уже были прекращены), сожителем наследодателя. Безусловно, каждый случай индивидуален, но всегда нужно стремиться к обеспечению принципа социальной справедливости, особенно при обсуждении вопроса уменьшения их обязательной доли или отказе в ее присуждении.

Руководствуясь п. 4 ст. 1149 ГК РФ отметим, что удовлетворение иска об отказе в присуждении обязательной доли или ее уменьшение обуславливается, исходя из следующего.

1. Спорное имущество использовалось наследником по завещанию для постоянного проживания или как основной источник дохода.

2. При жизни наследодателя спорное имущество наследником, имеющим право на обязательную долю, не использовалось.

Но в данном условии, по нашему мнению, заложена некоторая правовая неопределенность, так как в нем не установлено критериев оценки продолжительности использования имущества.

3. Реализация права на обязательную долю в наследстве сделает невозможной передачу спорного имущества наследнику по завещанию, если, например, наследственное имущество не может быть разделено без изменения его назначения, исходя из своих свойств.

4. Если имущественное положение наследника, имеющего право на обязательную долю, дает возможность уменьшения ее размера или отказа в присуждении.

Отметим, что законодатель, понимая сложный характер наследственных правоотношений, значительную роль в их разрешении отводит судебным органам. В связи с этим, полагаем возможным предложить внесение дополнений в действующую редакцию ст. 1149 ГК РФ, предусмотрев в ней положение о том, что суд, принимая решение по данному вопросу, вправе рассмотреть имущественное положение наследников, обладающих правом на обязательную долю. В частности, уточнить наличие у них собственного имущества, их участие в образовании общей собственности с наследодателем, совместное пользование ею, срок нахождения в браке, а также иные обстоятельства. И только руководствуясь полученными данными, принимать решение об уменьшении размера обязательной доли или отказе от ее присуждения. 


\section{ЛИТЕРАТУРА}

1. Гражданский кодекс Российской Федерации (часть третья) от 26.11.2001 N146-Ф3 (ред. от 18.03.2019) // Собрание законодательства РФ. 2001. 49. Ст. 4552.

2. Определение Судебной коллегии по гражданским делам Верховного Суда Российской Федерации от 05.11.2019 N5-КГ19-181 // СПС «Консультант Плюс».

3. Гущин В.В., Дмитриев Ю. А. Наследственное право и процесс. М.: Эксмо, 2007. С. 124.

4. Гришаев С. П. Комментарий к законодательству о наследовании // СПС «КонсультантПлюс».

5. Демина Н. Б. Обязательная доля как средство обеспечения прав родственников наследодателя // Нотариус. 2005. N4. С. 26.

6. Иоффе 0.С. Советское гражданское право. Л.: Изд-во Ленингр. ун-та, 1965. Ч. 3. С. 317.

( Гудков Анатолий Иванович ( gudkovaniv@yandex.ru),

Красильщиков Анатолий Владимирович ( krasilschikov@inbox.ru ), Мищенко Вячеслав Иванович ( vyacheslav-mischenko@mail.ru ).

Журнал «Современная наука: актуальные проблемы теории и практики»

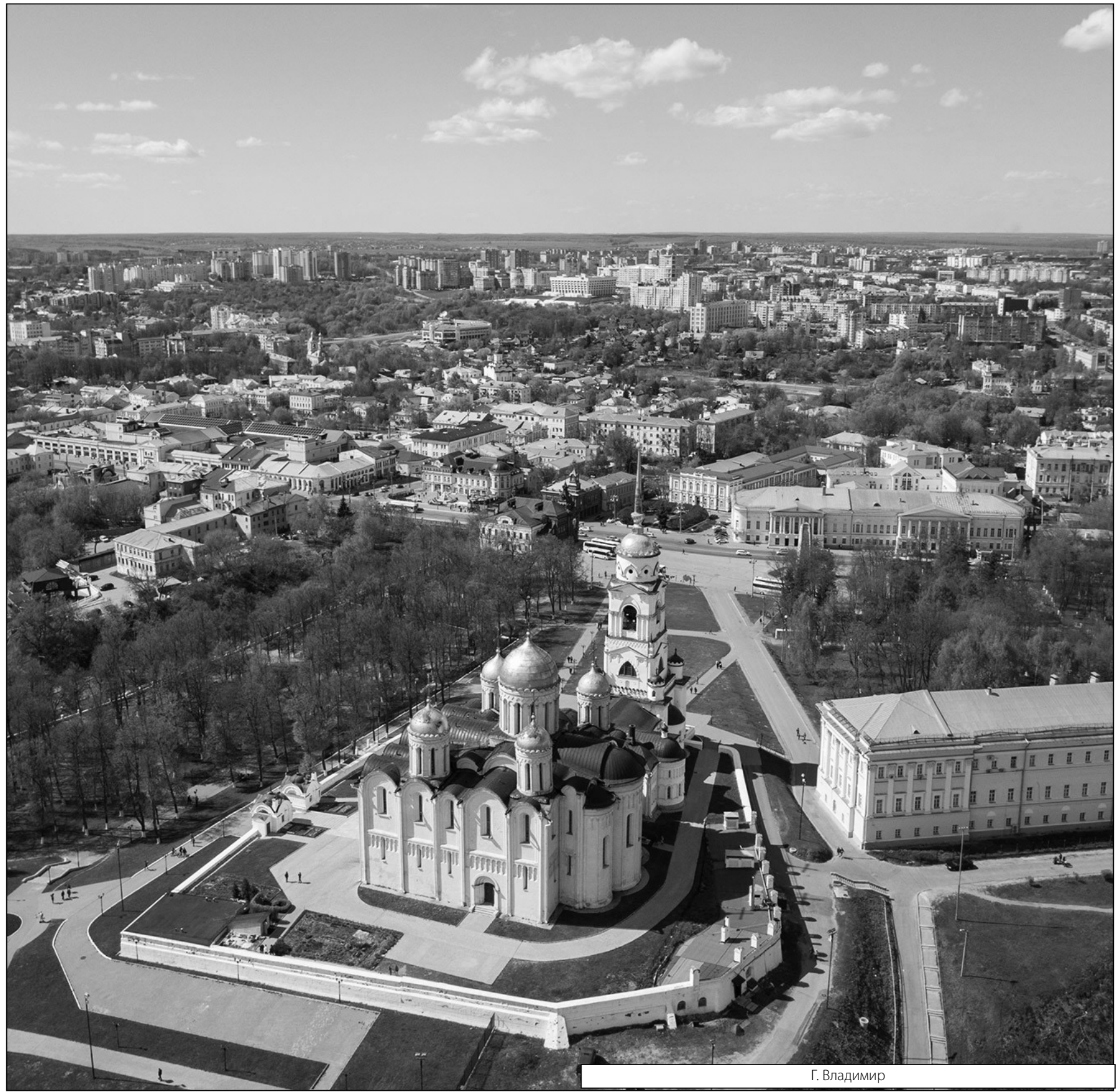

